orests of the coastal plain region of the southeastern United States are among the most productive in North America. Because they form the basis of a large timber and wood products industry, these forests are of considerable economic importance. Also, the forests are rich in plant and animal species. Because they are diverse as well as productive, they have considerable conservation importance. Therefore, understanding potential impacts of climate change on southern forests is critical.

Scientists from Rice University sponsored by the National Wetlands Research Center are using a long-term study of forest structure and change in east Texas to investigate potential effects of climate change on forests of the coastal plain (Fig. 1). Study areas include sites in the Big Thicket of east Texas, which are representative of important vegetation types on the coastal plain, including bottomland hardwoods, one of the two major types of forested wetlands in the region. Unique records of forest variation have been created for three study sites. The database includes records on more than 42,000 individual trees.

\section{Tree-ring Studies}

In addition to the long-term study, they use tree-ring measurements and weather data to reconstruct past relationships of tree growth to climate and to investigate species behavior near range limits. Annual tree-ring chronologies have been developed from 16 tree species growing on 38 sites distributed across the region. Initial results of tree-ring measurements indicate that individual growth is not substantially slower near the range boundary of a species, which implies that species range boundaries in this region are not set by climatic limitations on individual growth. Thus factors influencing reproduction may be more critical in setting range limits. Also, analysis of the relationship of tree-ring width to climate revealed

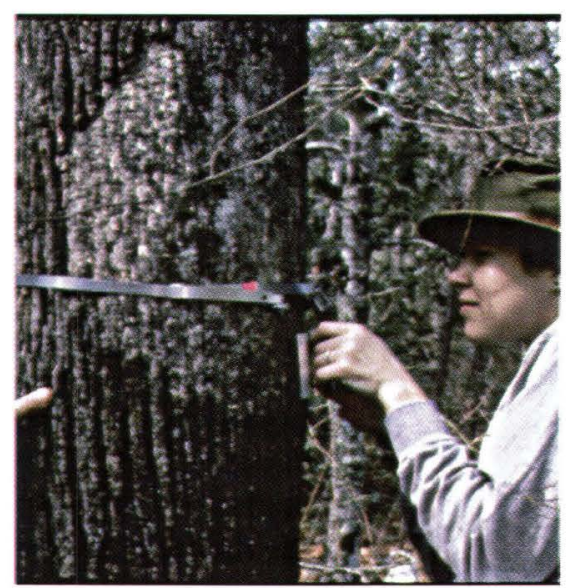

Fig. 1. Rice University researcher measuring tree growth at Big Thicket National Preserve.

another surprising result: several groups of related species (black oaks, white oaks, and pines) respond differently to climate. This fact indicates that groups will respond differently to climate change, and therefore the relative importance of these groups in forests may change. This kind of information is presently only possible to obtain through treering analysis.

\section{Effects of Flooding and Fire}

Long-term studies reveal that Big Thicket forests can show strong variation in tree mortality over time (Fig. 2). Flooding at the wet site in 1989-92 initiated a strong pulse of mortality. At the moist upland site, a hurricane caused a mortality peak in
1987 that was about three times the long-term average. Variations in abundance of saplings of some species (Fig. 3) are partially explained by these disturbances. For example, Chinese tallowtree, an exotic species, took advantage of the disturbance openings to invade the wet and the moist upland sites. Also, other species increased in abundance following the disturbances. Nevertheless, not all of the trends in saplings were related to these disturbances. At the wet forest site, it appears that changes in the river flow related to construction of two upstream dams much earlier

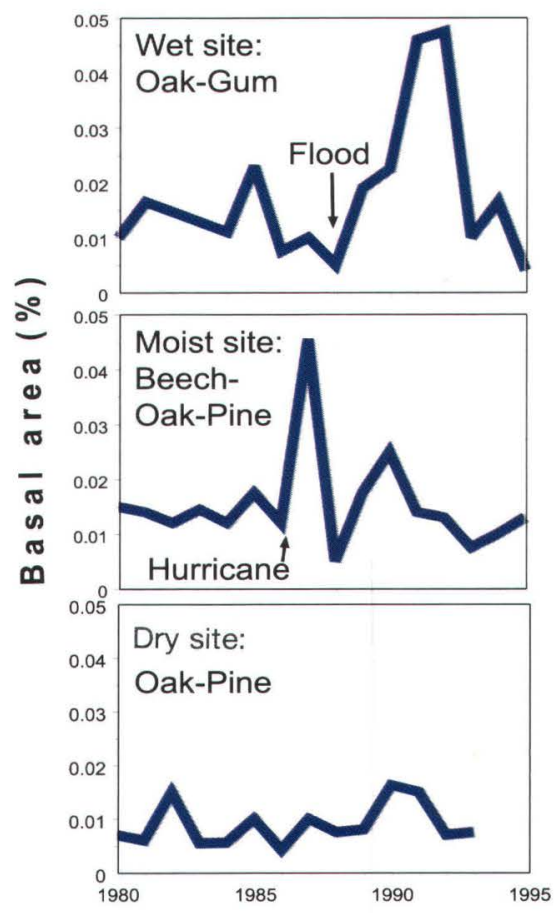

Fig. 2. Natural forest mortality. 


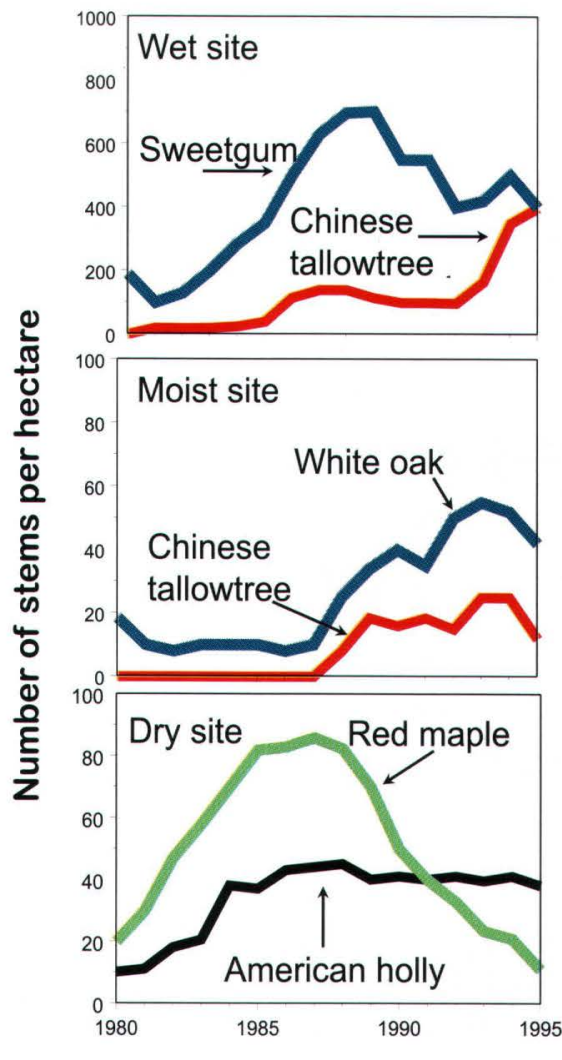

Fig. 3. Small sapling abundance.

favored sapling survival, resulting in an overall eightfold increase in sapling abundance and strongly altering the open understory that is characteristic of many bottomland forests. Altered river flows may also be predisposing this system to uncharacteristic increases of certain tree populations; these increases are then followed by catastrophic declines after unusual floods. Changes in regional climate will further increase this variability if they increase the frequency and intensity of both floods and droughts. Increasing variability of this type could result in altered ecosystem function in wetland forests and could also influence success of post-harvest regeneration in commercial forestry operations.

At the dry study site, the changes in sapling abundance were related to the history of human activity (logging and fire exclusion). Future effects of climatic changes on sites such as this will probably involve interactions between climate and fire regimes.
Changes in climate influence both within-season timing and intensity of fires, even under managed conditions, thus affecting forest composition.

\section{Effects of Storm Disturbances}

At the moist site, researchers directly observed the effects of a 1986 hurricane. Even though it caused only a small rise in mortality of canopy trees, this storm had an important impact on the forest by creating canopy openings which promoted growth of a non-native woody species, as well as several native species. If large storms begin to occur with increasing frequency, however, small trees and shrubs may benefit most, with detrimental consequences for canopy tree regeneration. This suppression of tree regeneration, coupled with higher storm-related mortality, could result in a long-term decline in the carbon storage capacity of southern upland forests.

\section{Influence of Climatic Fluctuations}

Researchers tested for variability in growth of trees and saplings over short and long time periods and small and large areas that might be related to climatic fluctuation. The emerging conclusion is that climate variation does produce small but detectable effects on tree and sapling growth in natural forests. However, subtle climatic variability does not seem to affect recruitment or mortality, though earlier work showed that drought strongly increased seedling mortality in the wet forest. Failure to detect effects on tree mortality may be related to the fact that trees die slowly and that multiple causes are often involved. Continued collection of these important data over the next 1020 years will more definitively show how climate affects tree recruitment and mortality.

\section{Climate Change Will Affect Southeastern Forests}

Overall, evidence from the longterm monitoring indicates that climate change will affect individual growth rates directly by way of overall warming or change in regional moisture balance. Climate shifts will also affect death and recruitment rates indirectly by altering the frequency and intensity of stand disturbances. Results suggest that disturbance effects are stronger and more immediate than growth effects. Because individual trees grow quickly and species are not particularly long-lived, responses to climatic change may be rapid. In natural area preserves, Chinese tallowtree and other nonnative woody species will become more important if disturbances increase. In commercially managed forests, increasing disturbance rates may result in higher timber losses.

The variety of spatial and temporal influences on forest processes, coupled with uncertainties associated with climate prediction, makes it difficult to assess the effects of changes in climate on forest dynamics at the ecosystem level. Nevertheless, this research not only identifies specific climatic effects on particular life stages or processes, but it also provides critical information for improving our understanding of the context within which these effects occur.

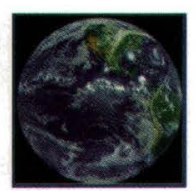

\section{For more information, contact}

Paul A. Harcombe

Rice University

Department of Ecology and Evolutionary

Biology

6100 Main Street

Houston, TX 77005

713-527-4924

harcomb@rice.edu

or

National Wetlands Research Center virginia_burkett@usgs.gov

http://www.nwrc.gov 